\title{
My adventures with Nick and Hannah: Anthropological explorations into sexdolls and the potential implications for human intimacy
}

\author{
Roanne van Voorst* \\ Anthropology Department, University of Amsterdam, The Netherlands
}

\begin{abstract}
This paper introduces two anthropological case-studies; one in which the (female) author personally rented a male sexdoll to experience, and one in which an owner of a sexdoll was observed in her house, interacting with her doll. Through the first case, in which the anthropological methodology of participation and reflection is used, it is explored what sexdoll-intimacy could look like for a heterosexual female. The second case study uses observation and in-depth interviewing to explore what sexdolls may mean for an atypical group of users: asexuals. Both case-studies serve to reflect on the potential positive impacts for human intimacy, as well as on potential challenges or concerns. It discusses the wider theme of intimacy and human relationships, using sociological literature on former important technological innovations and their societal impact. One of the major conclusions of the paper is that instead of focusing on the 'humanification' of robots and sexdolls, as is currently happening in this field of innovation, it is useful for social scientists to turn the topic up side down: focusing on the potential of robotification of humans. This also means a shift from focusing on the (possible) future, to current societal dynamics. Another conclusion is that, while social-scientific scholars have been largely critical on sexdoll innovations; it is equally useful to take a more descriptive approach and experience, rather than moralize, what sexdolls may bring individuals and the larger society.
\end{abstract}

Keywords: Future of sex, sex doll, sex robot, future of intimacy, sexuality, technological innovation, anthropology

\section{INTRODUCTION}

Although it is hard to estimate how many love/sex dolls are currently being produced and sold worldwide, it is certain that the number is growing quickly, just as is the case with sex robots - both the robots used in health care, hotel - and other services, as well as sex robots - used for intimacy and companionship (Levy, 2020, 35). The difference between a sexdoll and a sexrobot is that the latter have additional features due to a working, internal algorhytm, such as eye movements, facial expressions, other limited bodily movements (such as a raising and lowering chest, suggesting breath), and an audio option with limited, preset speech so that it can talk with its user. While sex dolls look the same - both dolls and robots are made from silicone and look rather realistic -, they cannot move or talk. This paper discussed two ethnographic cases with sex dolls - not robots - and hence the most part of the analysis will circle around dolls. However, as the literature often lumps both categories together, in the literature discussion I will sometimes refer to both categories (sex dolls and robots). In such occasions, I will indicate as clearly as possible which it is that I am discussing; I will also stick as much as possible to what is relevant and suitable to this particular paper.

Parallel to the worldwide increase in sex dolls and robots, the number of academic and public debates around their production and usage has grown - and these discussions have been heated. There are scholars predicting that soon, sex dolls and robots will be harder to distinguish from humans and, as

\footnotetext{
*E-mail: r.s.vanvoorst@uva.nl. 2589-9953 ( 2022 - The authors. Published by IOS Press. This is an Open Access article distributed under the terms of the Creative Commons Attribution-NonCommercial License (CC BY-NC 4.0).
} 
a result of these tech-innovations, will become much more commonplace in wider society than they currently are; there are also sceptics, underlining that the technological innovations needed for this development are no way near. There are academic proponents and scholarly opponents, and then there are non-scholarly activists involved in public debates - ranging from the producers and investors of sexdolls, to religious groups fearing them.

At one end of this academic spectrum, there are the voices of proponents of sex dolls, the most enthusiastic amongst them speculating that they are quickly becoming post-human bed-and love partners (Blizzard, 2018, Wong, 2015). A bit more towards the middle-line, scholars have argued that dolls and bots can serve to radically improve the intimate life of specific individuals and groups in society. Examples of target audiences that could benefit from the usage of dolls include soldiers and people who are imprisoned and would have no access to sex, otherwise McArthur (2018); disabled people (Di Nucci, 2017; Kim, 2012), sexually-traumatized people and people who, for whatever reason, may be unable to find a bed partner in real life and feel sexually frustrated or excluded, because of their involuntary isolation. One particular, but often mentioned example from this stream of literature, may be pedophiles: several authors have argued that childlike robots may be supportive in therapy for people with this sexual orientation (see for more on this discussion: Brown and Shelling, 2019; Behrendt, 2018; Danaher, 2017; Maras and Shapiro, 2018; Chatterjee, 2020). For all the abovementioned groups of potential doll-users, so the argument goes, sex dolls may serve a double function: they may not just alleviate a feeling of frustration for the individual user, but, as a result of it, they may also lessen (sexual) agression in wider society.

Another often-heard argument used by proponents of dolls and robots predicts that they may become substitutes for sex workers. Note that, in this line of thinking, the profession is typically portrayed as being inherently damaging for the sexworkers involved, physically and/or mentally (cf. FoschVillaronga and Poulsen, 2020; Yeoman and Mars, 2012). Therefore; it is considered good and important that these human sexworkers withdraw from the industry and sex dolls take over (see, however, for a critical reply to such ideas: Döring et al., 2020, and also van Voorst, 2022).

At the other hand of the spectrum, one finds the voices of academics and activists who warn for the potential downsides of current and future sexdoll-production and usage. One main issue raised by this group concerns the objectification of women that is mirrored in production of dolls, and the interlinked strengthening of (or protection of the status quo) of patriarchal powers in society.

These arguments stem from the fact that currently, by far most of the available sexdolls are female in shape, mirroring stereotypical images of female beauty and sexuality (young, big-breasted, smallwaisted, flawless skin, etc.). Not only are the looks of these dolls unrealistic, so the criticizers argue; their 'behaviours' are, too - unlike real humans, sexdolls are always willing to please their bedpartners; they don't need be asked for consent, and they never suffer from PMS or headaches. Scholars including Cassidy (2016), Döring and Pöschl (2018), Ferguson (2010) and Robertson (2010) predict that, if these sexdolls become more common in society, young women - already known to increasingly struggle with bodyshame - may become even more insecure about their physique and sexual attractiveness, as they cannot compete on many levels with 'perfect' sex dolls.

Moreover, authors have warned that users of sexdolls may become more sexually agressive towards real human beings, and rape may thus become more common, as the robots essentially train users to have sex with other beings without any need for consent (cf. Cox-George and Bewley, 2018). Therefore, this group of authors speculate about how future dolls and robots should look like and how they should behave: more realistic in appearance, and more sexually assertive and autonomous in behaviour, for example (Sparrow, 2017). 
These academic discussions are hugely important in an age where technological innovations move fast. Especially if these innovations concern factors that are so central to the human experience: intimacy, social relations, love, and sexuality. One could argue that these issues make humans, human - they steer our reproduction and hence our survival as a species, but more than that, even: during our lives, being in love or feeling aroused can make us feel alive as little else can. Humans are sexual beings, and if the human experience of sexuality is changing due to the rise of sex dolls, then this might mean that the human experience itself is changing.

However, at this moment, the debates in academia still lack real-life experiences and non-normative, descriptive analyses. As far as I am aware of, the far majority of scholars that has so far contributed to the growing literature on sex dolls, has written from a top-down or outsider perspective, where literature and analyses of small case studies (for example: research on small-scale tests with childrobot therapy) is used to come up with a normative argument. These authors, I want to stress, discuss hugely important ethical dilemmas and thus their contributions have been of great value. Yet I want to pose that at the same time, these perspectives lack an insider, bottom-up perspective; they are prescriptive, rather than descriptive.

Therefore, this paper aims to contribute to the discussion through the presentation and analyses of two anthropological case-studies. One is a case in which the author reflects on the time where she rented a male sex doll. The second is a case in which the author observed an owner of a sex doll for several hours in her house, interacting with the sexdoll. Crucial for this casus is that the owner of the sexdoll defines herself as asexual: her sexdoll functions as a companion doll. Next to observations and reflections, the second case was built on several in-depth, semi-structured interviews with the owner of the doll.

These both bottom-up, descriptive experiences, rather than only the academic or philosophical debates that are introduced in this paper, will serve as the basis for my attempt to contribute to a broader discussion on the future of human intimacy and sexuality: its opportunities and its challenges. The method used for the research is known as participant observation in anthropology and further explained below (section: methodology). After introducing the case studies, a set of theoretical ideas is discussed that are helpful to explore the topic of intimacy and (future) human relationships. Thereafter, the analysis serves to connect the author's experiences with the theoretical concepts.

Finally, the paper presents two major conclusions, one relating to the contents of the sex-doll debates and the other to the way in which the debate is now pursued. One conclusion is that instead of focusing on the 'humanification' of robots and sexdolls, as is currently happening in this field of innovation, it is more useful for social scientists to turn the topic up side down: focusing on the potential of robotification of humans in society. This robotification, here, refers to an unlearning of specific human skills, particularly on complex communication and cooperation, which could lead to a weakening of social ties and solidarity in society. The conclusion thus implies a change of focus, from the future to the now. Another important conclusion is that, while many social scientists have been largely critical on the sexdoll-and robot-innovations (arguably for good reasons); the case presented in this paper shows that it is also useful to take a more descriptive approach and include one's own experience, rather than moralize from the outside, what sexdolls or other sex-related innovations may bring human individuals and society.

\section{METHODOLOGY}

The author of this paper has obtained a PhD. in anthropology (cum laude) in 2014, and has specialized over the past two decades in research on future scenarios. The data on which this paper is based were 
collected during her anthropological fieldwork in the research area conducted in 2019-2021, as well as on data that was derived in the same years through interviews with experts, and visits to digital platforms for sexdoll users, such as dollharem.com. Moreover, a literature study was carried out, and notes were kept in a program called Zotero to keep track of the database of academic articles, scholarly debates and books.

Most importantly for this paper, the method of participant observation was used: a qualitative research method, mostly used in the discipline of anthropology, which involves personal and extended immersion in a culture or group and participation in its day-to-day activities. The downside of the anthropological method is that it leads to subjective research, which is hard to generalize. The upside, however, is that it offers bottom-up insights of actual human practices, descriptions of what happens on the ground, rather than normative ideas on what should be happening.

\section{CASE-STUDY 1: RENTING A SEX DOLL}

I had first tried to rent a doll in a brothel in Barcelona, but, after booking (without payment) and arrival from my hometown in the Netherlands, suddenly I could no longer get in touch with the brothelhouse. It appeared that it had been closed some days before, after neighbours had complained. This indicates that, while dollhouses are indeed popping up in more and more places around the world, they are still taboo for many citizens and not always welcomed. A few months later, in Austria, I made another appointment with a preselected doll -and this time, I was welcomed in. In order to do research in line with common anthropological ethical guidelines, I had introduced myself beforehand as a writer and researcher to the brothel owners. At the same time, I paid the regular money for an hour of usage of the doll.

In this particular dollhouse, nearly all of the dolls were female; one was male. Being a heterosexual female, I decided to opt for the male doll, who, according to the website, was named Nick, fond of rock-climbing and was the proud owner of a sixpack. Beforehand, I was asked over Email whether I would like to see porn through a Virtual Reality headset. I did, but then discovered that near all porn was focused on males penetrating females, seen from the male perspective (thus looking at the female while having sex with her). I wrote that I'd rather look at a male, and the owner finally suggested I would watch gayporn - he did not have anything else. Hence, it seemed to me that both the dollinventory and the film-stock was mostly focused on male, heterosexual customers.

Once arrived in Austria, I was sent the address of the dollhouse in a text message. An employee of the brothel let me in. He spoke very little English (while the Email-conversation with the owner had been in fluent English) but seemed kind and showed me the way to the doll of my choice: Nick. Enthusiastically, he opened the door to what seemed a small, rather dark hotelroom and shouted out that 'Nick has very big cock'. He did, indeed, as I could see: Nick was lying starfish-pose on a bed, his penis erect and pointing upwards, and - weirdly enough, as he still had hair when I selected him on the website - his head was completely bald. I was shown lubricants and the VR-machine, a shower, and then the employee left me in the room with Nick. I had booked him for two hours and suddenly had no clue what to do with all that time. Actually having sex seemed no option, though beforehand I had seriously considered that option and at least wanted to try to get somewhat intimate to a doll: Now, I felt repelled. It wasn't just his lack of hair, nor his frightingly big penis; while the doll looked extremely realistic (as a human being), he also certainly appeared more 'dead' than I had imagined. For instance, he wore metal pins in his feet, which stuck out of the soles, and his fingers felt weirdly soft and mushy (so I noticed, when, after I had taken off my coat, I dared to touch the doll's body). 
Eventually, I got more intimate with Nick. I lay down on the bed next to him, tried to hug him, but noticed that he was so heavy that I could not move him. I then lay my head on his chest - the skin felt cold. I noticed I was talking out loud and making jokes about the situation - admittedly, also about him, calling him a modern Jesus (because of the pins in his feet and hands) and telling him that it wouldn't do for me: "having sex with a dead guy with a boner"(I videod my own comments). In other words: I was being unkind to the doll with whom I had planned to have sex when booking him. One reason was my own awkwardness with the situation: joking helped me to be more at ease. The other reason was Nick. He felt un-human, to me, and so for obvious reasons I felt that I could treat him without any regards for emotions, feelings or ego. Still: it felt a bit mean to speak out these words, or pick up a finger or wiggle a toe without permission and then laugh at him because it looked weird. Hence: I was projecting human feelings onto the doll and while I did not experience much compassion, I still felt a sense of guilt.

After an hour or so, lying with Nick, talking to him, sometimes touching his body with my hands (and yes, I touched his penis, but not in any erotic way, more in the way a cat ticks a moving target with his paw), and silently reflecting on my inner experience, I tried the VR-headset, which worked fine enough, but the porn still wasn't making Nick more attractive, took some photos, and left Nick earlier than the full time I had paid for: I had become too bored to sit out my time.

\section{CASE-STUDY 2: OBSERVING AN ASEXUAL OWNER AND HER SEXDOLL}

She bought her sex doll when the hard lockdowns begun in the Netherlands, explains owner N. when I visit her in her house. N. approached me on Instagram after she found out about my research on this theme. She is an owner of a sexdoll, but a type of owner that may be called a surprising target audience: $\mathrm{N}$. defines herself as asexual, a term referring to the lack of sexual attraction to others, or low or absent interest in or desire for sexual activity. It may be considered a sexual orientation or the lack thereof. According to N., she has never been interested in sex with others (she does masturbate, as many other asexuals do, but considers that 'non erotic': it is, to her, a physical, purely functional activity that can help her fall asleep or relax in stressful times). She invited me to visit her in her house to meet her and her sex doll, Hannah. We decided to have lunch together and she agreed that I could interview her, and also that I could stick around for some hours to observe how she lives and interacts with Hannah.

N. is an artist of 39 years old, living in The Hague with her two cats. She has been in different romantic relationships earlier in her life, but has been single for the past four years: something that she regrets. According to N., she would very much like to spend her life with a romantic partner, but it is hard to find someone who can deal with her asexuality. N. is academically educated and successful in her work: at the time of my visit, she has several assignments and prepares fora $\mathrm{n}$ exhibition. She is beautiful, with long hair and an athletic build, welcoming and thoughtful in her answers. After our meeting, she appears extremely helpful: she sends me useful links to books and papers that we discussed.

During our lunch and throughout the interview, sex doll Hannah is sitting on the couch a meter or soa way from us, while we are sitting at the table. She is dressed in trousers and a flowery blouse, and wears a red bobline-wig. Both $\mathrm{N}$. and I look at the doll quite often when we discuss her or mention her - she appears to be halfheartedly part of the conversation, as though she were listening in whilst watching television. 
Hannah costed N. a thousand Euros, says N. She decided to invest in Hannah during the hard lockdowns in the Netherlands. She had initially saved that money to go to Japan for an art project, but when traveling became restricted and it dawned upon here that the lockdowns could mean that she would be alone for many months to come, she decided to spend her money otherwise. She has always been fascinated by dolls, N. explains; and indeed, in her living room I discover several other dolls: from mannequins to children's dolls. She had read about the existence of sex dolls in online articles, and couldn't get the question of off her mind: could a doll help her feel less lonely during lockdowns? When finally ordering her own doll, she opted for the tiniest version: Hannah was the cheapest of all dolls available.

Being asexual, N. is not interested in any sexual functions of the doll. "She has a vulva and an opening in her mouth, but I try to ignore that - I dressed her immediately in clothing after she arrived so that I don't have to be confronted with her genitals", says N. She also does not talk to her, although she underlines that she well understands that many other sex doll owners do: "I' $m$ just not that talkative, I don't talk to my cats either." That does not mean she is not physically intimate with her doll. N. describes how much she likes to dress Hannah into new clothing or put her in different positions to photograph her, an activity that appears to be a type of meditation for her: "Sex dolls are quite heavy - Hannah weighs 45 kilos or so. So it takes all my focus to move her around, or to hold up her arm while putting on a cute T-shirt. I brush her hair, too. It calms me down, to be occupied with her like that. I will decide to make a new photo, and then I get busy and suddenly, it's four hours later." She also often lies on the couch with her doll, admits N. when I ask her whether Hannah managed to decrease her loneliness, as she hoped for: "She does. Especially in the evenings, when I lay my head in her lap. Then, when I put her hand over my head, I feel the weight of her arm, and it feels like I am safe, and accompanied by someone I can trust". This typically takes a few minutes, N. adds: "Hannah is made from silicone and she feels cold, but after a while her skin will take on the temperature of my head, and then it feels real, and I feel less alone."

She is happy with her investment, N. tells me as we say goodbye. Even after the lockdowns ended, and $\mathrm{N}$. is seeing her many friends again, she has not done away with her. "Of course I am well aware that Hannah is not a human, let alone my partner. She is a doll. Perhaps she functions in the way other lonely people use a television: by having that blast all day, it feels like you are not so isolated. When she is sitting near me, I feel less lonely, so I will keep her even if I don't really need her anymore, now that lockdowns have passed. I've grown attached to Hannah. I can't even think of her not living with me."

\section{THEORETICAL FRAMEWORK}

In order to provide an ethnography of sexdoll usage, this paper builds upon (in a manner that is both appraising and critical) the argument of a historian called Jacob Burckhardt, known as the Burckhardt paradox. The idea coined by Burckhardt is that increased sophistication of material social conditions have, in modernity, been accompanied by an impoverishment of social relations. To put that in slightly different words: according to Burckhardt, the more complex the material conditions of a society become, the coarser its social relations become. This idea was later elaborated by Richard Sennett, when he looked at social and material dynamics in work environments. As will become clear in the analysis of this paper, both of their approaches are rather top-down and normative. The anthropological methodology underlying this paper, in contrast, leads to a bottom-up descriptive approach. Therefore, in below paragraphs I will first set out the main threads of the Burckhardt perspective, via brief dis- 
cussions of the works of Burckhardt himself, and Sennett. Next, in the analysis, I will contrast my empirical findings with their ideas, leading to a critical assessment of the theory.

In order to understand the roots of the Burckhardt-paradox, it is helpful to contextualize it in history. Burckhardt perceived history as the playing field of three opposing and influencing forces: culture, state and religion. In Burckhardt's time, the nineteenth century, emerging nationalism seemed to deny the mingling of peoples and the multiple identities of individuals in each nation. Yet at the same time, the nineteenth century was also the great century of industrial development and productive technology. Burckhardt linked these two developments in the paradox of an industrial technology tending towards the complex and a nationalism tending towards the, in his wording, "terribly simple". To build his argument, he developed a vision of the great developments in human civilization spanning many centuries. He thus emphasized the importance of historical knowledge and the value of diversity in art and culture production, warning against the flattening of culture and the rise of mass movements, populism, nationalism and militarism. He pessimistically described modernity as the "age of terrible simplifiers."

Two centuries later, in 2010, the renowned sociologist Richard Sennet translated this wider, societal idea into an updated and much more specific, narrow version in his text Humanism, The Human Being as Work in Progress. Focusing on different work environments (Sennett and his team of researchers conducted fieldwork in the City in London, whilst Sennett also describes a casus in which he was able to observe firsthand what happened in the Google Wave department), Sennett firstly points out that the complexity of computers, algorhytms and other innovations has gotten to the point that it is beyond our capacity to make good use of them. This is noticeable especially in the phenomenon that they seem to make it harder for us to establish true cooperation between different people in roles within a company. Often, within a company, only few programmers are able to grasp the new technology in use - and even for them it can be hard to understand algorhytms. Yet at the same time, many different staff members need to take decisions about this new technology. So, crucially, the programmers and other stakeholders need to cooperate in order to obtain optimal results: ideally they would both learn from each other. To give but one example: managers would learn more about programming, whilst programmers would learn to understand better the decisions that are going to be taken in-company on the basis of the new technology-use they install. This, observes Sennett, does not happen. Instead, with the rise of complex technology, staff in companies begun to cooperate less - or not at all.

Modern society, then, creates a material complexity it does not know how to use. Sennett indicates that this has two important downsides. First, it creates a dysfunction in which workers in companies operate in isolation without effectively communicating with each other, or even by communicating only to a minimum. This leads to work without cooperation, which, eventually, is detrimental to the organization as a whole. Secondly, Sennett suggests - somewhat implicitly - that because we lean more on technology and less on intrahuman communication and cooperation, the human capabilities that we need to get specific jobs done, weaken. In other words: workers in many companies are becoming less good in capacities that are typically needed to reach success (complex communication and cooperation), whilst computers are supposed to take over those tasks or make them less relevant, but because we don't really understand how the computers work and what the effects of their actions are, we often end up with weaker organizations ánd weaker individuals.

An example is useful to grasp better this idea: Sennett and his research team spent two years studying the communicative relations between managers and subordinate technicians, namely programmers who designed algorithms applied to derivatives. Sennett concluded that the managers had by far not enough understanding of the mathematics involved in the algorhitms. Therefore, as long as things seemed to go well in their departments and profits were made, they often turned a blind eye as to 
what was going on. Of course, this had a potential danger to it as well: if things would go wrong, the managers would not be able to grasp what went wrong, or why - let alone how to solve the issue. They were fully dependent on the programmers. At the same time, they were hardly in contact with them - communication between managers and in-company technical experts was happening much less then in the years before, when the technical experts were still working on technology that was relatively easy to apprehend for lay people. In the few occasions that technical staff received questions from managers about the algorhytms they built, the programmers had to radically simplify their language towards managers. As such, they simplified decisions, issues and problems in their upward communication - the managers were not aware of this.

This had a double-sided effect: first of all, the programmers practiced less in complex communication with managers, which, over time, might decrease their capacity to find language that resonates with non-technical experts. This expectation of Sennett is related to what anthropologist Arjun Appadurai (2004) has written about the 'capacity to aspire' - a human capacity to aspire a better future and that, he claims, strengthens when one practices it (as often happens with well-off children or adults in social environments full of resources and positive, inspiring examples) but weakens or does not even develop when one doesn't get to practice it (as is more often the case with poor communities, where dreaming about a radically different, better life is considered - and probably is - unrealistic).

A second effect of the rise of complex technology, in the observation of Sennett and his team of researchers, was that there remained hardly any direct, effective communication or cooperation between manager and programmer, but there was much indirect communication that appeared destructive to cooperation. Those who could do math challenged the legitimacy of their superiors and communication increasingly took the form of passive-aggressive jokes or gossips behind the managers' backs. This all led to a situation where, when the firm would be finally ready to collapse, there was no solidarity to be found between the different layers of employers and it would be harder to save the company.

In summary, the arguments of Burckhardt and Sennett hold that whilst innovations become more complex in different fields of society, they progress faster than most humans can process, and as a result, in many environments that were expected to thrive through a hybrid of man and technology, instead, we see social relations deteriorate, while human capabilities to communicate and cooperate effectively weaken. It is in this context of inversion of the relationship between competence and hierarchy that inequalities lead to savage simplifications, as cooperation disappears and consequently, the complex web of confidence, trust and mutual respect loses its density and structure. The organization or society becomes more unstable, both for the lack of true cooperation, and for the weakening of individual's social capabilities.

More recently, other scholars have also argued that modern technology can and does affect and change our human behavior, and even impacts our experience of living in this world. But, in contrast to Burckhardt and Sennett, they also discuss observed or potential positive effects of the use of complex technology, for both individual and society. Importantly, it appears from their work that these positive effects occurred even if the humans making use of the technology did not fully understand it. Philosophers Miriam Rasch and Peter-Paul Verbeek present many examples in their respective writings: the birth control pill led to safer and freer sex; the washing machine to more free time for women; the plane turned those who can afford to travel, into cosmopolitans; the language-suggestion-option in Email programs like Gmail makes our language uniform - one with a surprising number of exclamation points: "Great, thanks!"; "Looking forward!” (Rasch, 2020; Verbeek, 2018).

One personal example may be useful, here, too: I used to know all the phone numbers of friends by heart, but nowadays I don't recall any of the phone numbers of my friends (or family, or my partner), 
simply because I no longer have to train that memory part - they are stored in my phone anyway. This may indicate that I have unlearned something (remembering phone numbers). However, that does not necessarily be a negative outcome for society, as the innovation of the mobile phone also makes it easier to contact acquintances any time of day, to communicate whenever wanted, and thus strengthen the options for cooperation and tightening social ties.

This more nuanced, open perspective is, in my opinion, an important addition to the work of Burckhardt and Sennett because it allows to focus attention on the ambiguity of human technology-use, rather than merely on its downsides. Moreover, through the examples provided by Rasch and Verbeek it becomes more clear that outcomes can also be positive, even for humans who do not understand at all the technology they are using, as was for example the case with the birth pill or the washing machine.

Therefore, this article proposes that as technology becomes ever-more complex, and whilst most humans are still not always able to understand new innovations but use them anyhow, this can lead to a myriad of outcomes: both the unlearning or learning of specific individual capabilities, particularly those related to complex communication and human cooperation or solidarity. Likewise, it can also lead to negative or positive outcomes when it comes to larger society, where negative, in the argument built by Sennett, refers to a weakening of social ties due to ineffective communication and cooperation, and positive to a strengtening of social ties and human solidarity due to more effective communication and cooperation.

In what follows, I will connect the theoretical framework to the empirical findings of my fieldworkexperiences with two sex dolls.

\section{CASE-STUDY ANALYSIS}

Although the promises about the 'humanization'of sex dolls are sky-high and often presented as givens, my own experience with dolls taught me that at this very moment at least, the actual technology has not caught up with expectations. The doll I rented certainly looked like a real human at first sight, but it did not feel like one, nor did it behave like one. The sex doll reminded me more of an extension of a popular sex tool, like a dildo or vibrator, than a human bedpartner. The same was true for sexdoll Hannah, although her owner was least interested in her sexual functions: she was hard to move around, heavy, and her silicon skin was cold. On the basis of estimations of experts (Waardenburg, 2020; Beerends, 2020), it seems unlikely that this will change as much as often predicted, within 5 or 10 years.

This suggests, firstly, that the current debates on 'humanized' dolls overemphasize future, imagined and perhaps somewhat naive technology-possibilities, rather than that they deal with the issues that exist around modern realities. Novice research on artificial intelligence has proven that technology innovations are proceeding at much slower pace than was expected and hoped for Waardenburg (2020). This does not mean that there has been no innovation: the opposite is true, as becomes clear from recent demonstrations of machine learning abilities, such as Google search; nevertheless, it is way too far to speak of computerized, general intelligence.

In a similar vein, philosophers have argued that the whole discourse on 'smart' technologies and artificial 'intelligence' is misleading - it projects human abilities onto non-human computer systems; systems that are well able to recognize patterns or do maths, but that do not, at all, 'learn' or can be called 'intelligent' in the way that resembles human learning or intelligence (Beerends, 2020). Admittedly, some of the ideas in the literature may become relevant when tech would catch up with 
expectations and dolls would become more and more humanized: lighter-weight, more userfriendly and - most importantly - with doll-technology blending in with innovations in algorhitmic speechprograms and artificial intelligence in robots. If, indeed, the sex dolls of the future increasingly look, feel and behave like humans, it would be useful for scholars to overthink the ethical dilemmas and social consequences of the future. Nevertheless, it may be true that the current debates miss the actual point by spending so much time, academic funding, energy and words on radical technological innovations that may happen in the nearby future - or, that may not.

At the same time, the second case study (with sexdoll Hannah) and also my observations on dollfora like dollharem.com made clear that some of the current users of sex dolls don't need dolls to look, feel or act more human: they consider them as valuable companions already and truely care for them, indicating that they are emotionally attached to them and would miss them if they would be seperated from them.

If we would consider the impacts of dolls on individual lives and on society as a whole for what they currently are in shape, physique and technological level, they appear merely as either chic versions of sextoys rather than substitutes for real human bedpartners, as Nick is, or as companions for asexuals or lonely people longing for safe forms of intimacy with another being, as Hannah is, somewhat in the way a blasting television can offer companionship - not as a substitute for humans, but as a 'thing' that offers comfort. At the same time, on sexdoll fora and from newpaper articles about sexdoll users, it also becomes clear that some users do indeed already perceive the current versions of sexdolls as good alternatives to human romantic or sexual partners. ${ }^{1}$ These users may define themselves as pansexuals, as sexdoll owner Tolochko recently did (Cost, 2021). In any case, all of these users don't need their dolls to become more innovative or real: they are happy with them, as they are.

My guess is that, for a lot of the current opponents of sex dolls, sex dolls would feel less dangerous or damaging to society if we take the experiences of such current users into account. Dolls in the size and shape of children will most likely still stirr much concern (and maybe for good reasons), as pedophily is considered a major cultural taboo in modern Western society and associated with enormous suffering and emotional damage for children. But when it comes to the usage of adult dolls by imprisoned or disabled or otherwise lonely people who could otherwise not express themselves sexually, or who desire nonsexual, yet physical companionship by a different human being, it seems likely that the potential, felt threat posed by sex dolls would at least be balanced by more positive impacts for users. Please note that I am not proposing that academic debates focus less on the future and more on the current situation, to suggest that scholars overlook the importance of anticipating possible ethical dilemmas of the future. But I do think that by focusing so much on a future that may lie further ahead than what is commonly predicted by doll-producers and analyzers alike, scholars are missing important issues that already exist, now. I also believe that by sticking to expectations of the future, scholars tend to cling on to normative arguments, whilst present case studies enable us to describe the users' experience. This allows for surprising findings, like the comfort that sex dolls may bring to asexuals in society. It also allows for exploration of both negative and positive effects of sex dolls on individual users and society.

This brings us back to the theory and especially aformentioned Buckhardts paradox, as described by both Jacob Burckhardt (1905, 1955) and Richard Sennett (2010): the proposition that the more complex the material conditions of a society become, the coarser its social relations become.

\footnotetext{
${ }^{1}$ An anomymous reviewer also pointed me to the documentary movie "Guys and Dolls" from 2007, which gives room to user experiences.
} 
My experience with sex dolls suggest that reality is more subtle and complex than this. Starting with the case study of sex doll Nick - which is, admittedly, only my experience and therefore cannot be generalized: I consider my findings to be starting points for debate and stimulance for further research - I found that on an individual level, the interaction with a sexdoll may indeed lead to an unlearning of certain human capabilities. For example, typically a sexual relationship with a human partner demands we act in a respectful and friendly way towards that partner. Interacting with a doll, however, I noticed I had no issue making fun off the doll and touching his body in ways that seemed, even to me, unkind.

Would this suggest that sex with dolls could make us more agressive or unsocial to humans, too? That if we would interact with dolls, more and more, we would unlearn communication, leading to less cooperation and solidarity amongst humans? That learned unkind or disrespectful behaviour towards robots and dolls, will also begin to characterize relationships of humans? The answers to such questions are, of course, highly speculative. I am, however, personally unconvinced, exactly because the doll in the cases I studied, seemed nothing like a human; hence, I could very well feel the difference and doubt that I would behave equally unkind to a human being, than to a doll. Likewise, my research-participant $\mathrm{N}$. was well aware that her doll Hannah was a thing, not a human, yet in her case I found that she was behaving extremely kind and respectful towards her: making sure she looked well, brushing her hair, carefully moving her around, photographing her in flattering positions.

Burckhardt pointed out that new innovations sometimes flatten human interactions, an idea that is worth considering. What if we accept, for this moment, that dolls will not soon resemble humans; yet their popularity will increasingly grow, and within years we will see many more of them: in individuals' bed rooms, in brothels, in prisons, in hospitals.

If we would perceive this trend as a complete substitute for the human need for intimacy, we might indeed greatly reduce the human experience of sexuality. Sex with a doll is aimed at efficiency, frictionlessness and convenience. It can lead a user to a quick orgasm without going through the effort usually associated with real human contact. Even in the case of asexual N. and her Hannah the word 'frictionless' rings true, as do concepts as convenient and efficient: she was behaving kind enough to her doll, but never had to ask her whether she agreed with what $\mathrm{N}$. wanted her to do - something that would be the case with a human partner. Indeed, actual human relations are characterized by insecurity, the risk of rejection, vulnerability, awkwardness, having to learn what someone else finds arousing. That is what makes human sexuality so exciting, intimate and sometimes delicious - that is what makes the experience human, and most humans long for that complex experience, rather than for only the orgasm or the company.

Similarly, as long as sex with dolls is portrayed as a realistic and complete substitute for human contact, we reduce the services provided by sexworkers as something mechanic, rather than deeply human. Although it goes beyond the scope of this paper, my own interview data with both sexworkers and their clientele indicate that the far majority of people willing to pay for sex, do so not (just) for the orgasm or even the sex. Rather, they pay for human contact; for an hour or evening of uncomplicated fun; or, also common, for an opportunity to try out a fetish or sexual desire with a kind human being who happens to also be a professional in the game, and to live out the fantasy in a safe, non-judgemental - but still very much social! - environment. Substituting all sex work for dolls, as Yeoman and Mars (2012) have proposed for Amsterdam's red light district, seems a meager exchange for the clients.

As indicated, there are also current users who, unlike I did and N. did, do perceive their dolls as human substitutes. Unfortunately, it is completely unknown in academic literature whether they have begun to behave less kind to humans, or communicate less or cooperated less with them, than they 
did before they acquired or rented dolls. The opposite idea may be just as true: maybe the doll fulfills long-awaited desires, helping their owners to build self-confidence and feel less frustrated, which might again help them get in contact with other human beings and strengthen social relations. Hence, as scholars as Rasch and Verbeek remind us: the usage of technology, whether or not we understand it, can lead to negative or positive results for both individuals and society. We do know that there are dollowners who perceive their romantic dolls as 'real' partners, and also engage in romantic relationships with actual humans (cf. Cost, 2021), indicating that interaction with dolls does not necessarily have to be deteriorating of societal dynamics. Clearly, much more research is needed in order to gather data and understand potential impacts for individuals and society.

Although my anthropological fieldwork makes me doubtful whether increased human-doll interaction will lead to a decrease in quality of human-human interaction, and although I believe that the usage of dolls may be beneficial for some people in society, I want to stress that I do not perceive dolls as ideal solutions for most people, especially not when it comes to some of the pressing issues in our modern society. Perhaps people who feel they are unable to achieve intimacy with other human beings (and there are many, if we take that loneliness is a fast-growing problem in the modern world, see Hertz, 2020), should be offered support in the form of communication training and therapy, rather than in the shape of sex dolls. The same could be said for couples in which one partner has a different sexual preference from the other, as Cox-George \& Bewley also argued in 2018. Such training would arguably be beneficial for individual lives, and also for society as a whole; moreover, eventually I believe that for by far most people alive, succesfull and effective interaction with humans rather than dolls may provide a more complex, but also more rich and complete life-experience.

\section{CONCLUSIONS}

This paper presents two major conclusions, one relating to the contents of the sex-doll debates and the other to the way in which the debate is now pursued. One conclusion is that instead of focusing on the 'humanification' of robots and sexdolls, as is currently happening in this field of innovation, it is more useful for social scientists to turn the topic up side down: focusing on the potential of robotification of humans, by which I refer to an expected unlearning of capabilities that underlie a stable, succesfull society.

Another important conclusion is that, while social approaches have been largely critical, top-down and normative when discussing (future) sexdoll innovations; it is more useful to take a bottom-up approach and take seriously the present users'experience.

It needs to be absolutely clear that two single encounters of one single researcher with two sex dolls is far too limited an experience to draw any conclusions about 'the human' experience with dolls, let alone on the impact that future doll-innovations may have on 'human intimacy and sexuality'. This, again, means that case studies such as the ones presented in this paper contribute both nothing and a lot to debates about these themes, at the same time. Nothing, because every human experience with a sex doll is a highly subjective and personal one, and will thus vary with the user, influenced by a person's individual traits (motivation to try out new things, sexual orientation, political ideas, gender, etc.) as well as by the societal and cultural context in which such traits were developed.

But conversely, one might say it contributes a lot, though, because in the current academic debates, personal experiences of humans with dolls have so far not been used as the basis for argumentdevelopment. That is a remarkable and dangerous lack in the literature, if one considers that the 
topics of intimacy, sexuality and love are central to the human experience. Prescriptive and philosophical discussions are therefore not enough to help us think about what the development of dolls could mean for human society; we also need personal reflections and experiences, and more writing from that perspective - this paper aims to be an inspiration for that.

\section{ACKNOWLEDGEMENTS}

My deepest thank goes out to research participant N., for her trust and openness. I also want to thank mrs. Gabriella van der Linden for her solid contribution in the literature review, as well as three anonymous commentators for their useful tips and suggestions on the first draft of this paper.

\section{REFERENCES}

Appadurai, A. (2004). The capacity to aspire: Culture and terms of recognition. In V. Rao and M. Walton (Eds.), Culture and Public Action (pp. 59-84). New Delhi: Permanent Black.

Beerends, S. (2020). De Nieuwe Wereld Podcast.

Behrendt, M. (2018). Reflections on Moral Challenges Posed by a Therapeutic Childlike Sexbot. In A. Cheok and D. Levy (Eds.), Love and Sex with Robots. LSR 2017. Lecture Notes in Computer Science (Vol. 10715). Cham: Springer. doi:10.1007/978-3-319-76369-9_8.

Blizzard, D. (2018). The next evolution: The constitutive human-doll relationship as companion species. In A.D. Cheok and D. Levy (Eds.), Love and Sex with Robots: Third International Conference, New York, USA: Springer.

Brown, R. \& Shelling, J. (2019). Exploring the implications of child sex dolls. Trends Issues Crime Crim Justice, 2019(570), 1-13.

Burckhardt, J. (1905). Reflections on History. No Publisher.

Cassidy, V. (2016). For the love of doll(s): A patriarchal nightmare of cyborg couplings. Eur Soc Cardiol, 42(1-2), 203-215.

Chatterjee, B.B. (2020). Child sex dolls and robots: challenging the boundaries of the child protection framework. International Review of Law, Computers \& Technology, 34(1), 22-43. doi:10.1080/ 13600869.2019.1600870.

Cost, B. (2021). Bodybuilder who wed two sex dolls is now open to dating humans. New York Post, 31 May. Accessed 18 August, 2021, URL: https://nypost.com/2021/05/31/bodybuilder-who-marriedsex-dolls-now-open-to-dating-humans/.

Cox-George, C. \& Bewley, S. (2018). I, Sex Robot: The health implications of the sex robot industry. BMJ Sex Reprod Health.

Danaher, T. (2017). Robot Sex: Social and Ethical Implications. MIT press.

Di Nucci, E. (2017). Sex Robots and the Rights of the Disabled. In J. Danaher and N. McArthur (Eds.), Robot Sex. Social and Ethical Implications (pp. 9-23). Cambridge (MA): MIT Press.

Döring, et al. (2020). Design, Use, and Effects of Sex Dolls and Sex Robots: Scoping Review.

Döring, N. \& Pöschl, S. (2018). Sex toys, sex dolls, sex robots: Our under-researched bed-fellows. Sexologies, Jul, 27(3), e51-e55. doi:10.1016/j.sexol.2018.05.009. 
Ferguson, A. (2010). The Sex Doll: A History. Jefferson, NC: McFarland \& Company.

Fosch-Villaronga, E. \& Poulsen, A. (2020). Sex Care Robots: Exploring the Potential Use of Sexual Robot Technologies for Disabled and Elder Care. De Gruyter.

Hertz, N. (2020). The Lonely Century. Coming Together in a World That's Pulling Apart. New York: Currency.

Kim, E. (2012). Why do dolls die? The power of passivity and the embodied interplay between disability and sex dolls. Rev Educ Pedagog Cult Stud, 34(3-4), 94-106. doi:10.1080/10714413.2012. 686852 .

Levy, D. (2020). Intelligent no-fault insurance for robots. Journal of Future Robot Life, 1, 35-57. doi:10.3233/FRL-200001.

Maras, M. \& Shapiro, L. (2018). Child Sex Dolls and Robots: More Than Just an Uncanny Valley. Journal of Internet Law.

McArthur, N. (2018). The case for sexbots. In J. Danaher and N. McArthur (Eds.), Robot Sex: Social and Ethical Implications (pp. 3-18). Cambridge, MA: MIT Pressm.

Rasch, M. (2020). Frictie. Amsterdam: De Bezige Bij.

Robertson, J. (2010). Gendering humanoid robots: Robosexism in Japan. Body \& Society, 16(2), 1-36. doi:10.1177/1357034X10364767.

Sennett, R. (2010). De Mens Als Werk in Uitvoering. Boom: Amsterdam.

Sparrow, R. (2017). Robots rape, and representation. Int J of Soc Robotics, 9(4), 465-477. doi:10. 1007/s12369-017-0413-z.

van Voorst, R.S. (2022). Met z'n zessen in bed. De toekomst van Liefde: on robots. and on sexwork. Amsterdam: Podium.

Verbeek, P. (2018). Op de Vleugels van Icarus. Hoe techniek en moraal met elkaar meebewegen. Amsterdam: Lemniscaat.

Waardenburg, L. (2020). Slim managen van AI in de praktijk. Hoe organisaties slimme technologie implementeren. (Smart managing of AI in daily practice; how organisations are implementing smart technologies). Mediawerf Publishers.

Wong, N. (2015). Social Surrogates or Posthuman Lovers?: Love Dolls in the Robotic Moment. Open ULeth Scholarship (OPUS).

Yeoman, I. \& Mars, M. (2012). Robots, Men and Sex Tourism (Vol. 44, pp. 365-371). Futures. 